\title{
Endocrine complications in thalassemic children at a tertiary childcare hospital of South Punjab, Pakistan.
}

\footnotetext{
1. MBBS

Post-Graduate Resident Pediatric Medicine

Children's Hospital \& ICH, Multan

2. MBBS

House Officer,

Holy Family Hospital, Rawalpindi.

3. MBBS, DCH, FCPS

Associate Professor Pediatric

Endocrinology

The Children's Hospital \& ICH, Multan.

4. MBBS, FCPS (Paediatric Medicine)

Associate Professor Paediatric

Medicine

The Children's Hospital \& ICH,

Multan.
}

Correspondence Address:

Dr. Asim Khurshid

Paediatric Medicine

The Children's Hospital \& ICH, Multan.

asimkhurshiddr@gmail.com

Article received on:

20/07/2020

Accepted for publication:

$12 / 09 / 2020$

\section{Syed Zagham Ali', Sana Waqar ${ }^{2}$, Waqas Imran Khan ${ }^{3}$, Asim Khurshid ${ }^{4}$}

ABSTRACT... Objective: To find out the frequency of endocrine complications in thalassemic children at a tertiary care hospital. Study Design: Cross Sectional study. Setting: Department of Pediatric Medicine, "The Children's Hospital and Institute of Child Health (CHICH), Multan,". Period: August 2018 to May 2019. Material \& Methods: A total of 160 children of both gender and aged $2-14$ years having thalassemia major were enrolled from thalassemia center, $\mathrm{CHICH}$ Multan. Venous blood sample $(5 \mathrm{ml})$ was taken and dispatched to central institutional laboratory for performing specific investigations. Results: Majority of the patients, 101 (63.1 $\%)$ were male. Overall, mean age was $6.79+2.10$ years. Mean no. of transfusions in our study cases was $3.16+1.14$ while $128(80.0 \%)$ had to undergo blood transfusion more than twice per month. Parental consanguinity was positive in $122(76.2 \%)$. Mean Fasting blood sugar level was $117.28+32.43 \mathrm{mg} / \mathrm{dl}$ and diabetes was noted in 70 (43.8\%). Mean FT4 was $0.99+0.12 \mathrm{ng} / \mathrm{dl}$ and hypothyroidism was noted in 32 (20.0\%). Endocrine complications were noted in 102 (36.8\%) cases. Conclusion: Very high frequency of endocrine complications was seen among children having thalassemia. Endocrine complications were significantly associated with age, residential status, number of blood transfusions per month, disease duration and parental consanguinity.

Key words: Endocrine Complications, Frequency, Thalassemia.

Article Citation: Ali SZ, Waqar S, Khan WI, Khurshid A. Endocrine complications in thalassemic children at a tertiary childcare hospital of South Punjab, Pakistan. Professional Med J 2021; 28(9):1302-1307. https://doi.org/10.29309/TPMJ/2021.28.09.5704

\section{INTRODUCTION}

Thalassemia International Federation (TIF) estimates 200,000 patients of Beta-thalassemia ( $\beta$-thalassemia) alive around the world. ${ }^{1}$ Lack of genetic counseling as well as proper screening make $\beta$-thalassemia a major threat for the future. $\beta$-thalassemia is described as reduction in the synthesis of haemoglobin subunit beta (haemoglobin beta chain) which results in microcytic hypochromic anaemia, a deranged peripheral blood smear with nucleated red blood cells and reduction in haemoglobin $\mathrm{A}(\mathrm{HbA})$ depicted on haemoglobin analysis. ${ }^{2}$ Patients of thalassemia major are frequently found to accompany anaemia and hepatosplenomegaly and usually diagnosed below than 2 years of age. $^{3}$

If not treated, children with $\beta$-thalassemia have major failure to thrive along with shortened life expectancy. Majority of the patients having $\beta$-thalassemia need lifelong clinical management especially in the shape of blood transfusion and chelation therapy. ${ }^{4,5}$ Few of the patients having $\beta$-thalassemia have the option of curative but potential hazardous allogeneic transplantation of haematopoietic stem and progenitor cells (HSPCS). ${ }^{6}$

Due to regular transfusions and chelation therapy, endocrine abnormalities are commonly seen in these children with $\beta$-thalassemia especially in those who have major iron overload because of poor compliance to treatment, mainly following 10 years of life. ${ }^{7}$ Improving quality of life is the primary objective whenever management of a child with thalassemia is planned. Careful monitoring of growth as well as pubertal development is essential to mark abnormalities in order to start time treatment. ${ }^{8}$ Adil et al from Karachi has reported that $29.4 \%$ thalassemic children had diabetes, $11.8 \%$ had hypothyroidism 
while Satwani et al from Karachi also reported $57.14 \%$ children with thalassemia had endocrine complications. ${ }^{9,10}$

The rationale of this proposed study is to determine the pattern of endocrine complications in children with thalassemia as there is no such study done in our local population in last 5 years. Our study is being proposed with larger sample size so as to give more authentic and reliable information with aim to find out the frequency of endocrine complications in thalassemic children at a tertiary care hospital.

\section{MATERIAL \& METHODS}

This cross-sectional study was done The Department of Pediatric Medicine, The Children's Hospital and Institute of Child Health $(\mathrm{CHICH})$ Multan, from 11-08-2018 to 10-05-2019. Approval from Institutional Ethical Committee" was taken. Informed consent from parents/guardians of all the study participants was sought.

A sample size of 160 cases considering was calculated considering $\mathrm{z}=1.96, \mathrm{p}=11.8 \%$ (frequency of hypothyroidism) $^{9}, q=100-p$ and $d=5 \%$, through "formula; " $n=z^{2} p q / d^{2}$ ".

All 160 thalassemia major children of both genders and aged 2-14 years were enrolled. All children were confirmed cases of thalassemia and were on blood transfusion at least twice a month for more than 1 year. $\beta$-thalassemia major in children was diagnosed on the basis of fetal hemoglobin as more than $50 \%$ of total on $\mathrm{Hb}$ electrophoresis. Children with thalassemia minor or on specific replacement / hormonal therapy were excluded.

A special template was designed to record all the study information. All patients from Thalassemia center of $\mathrm{CHICH}$, Multan, who met inclusion criteria were enrolled. The $\mathrm{CHICH}$ has its own blood transfusion facility for thalassemic children in which there are already more than 400 children registered for regular blood transfusion. Venous blood sample $(5 \mathrm{ml})$ was taken and dispatched to central institutional pathology laboratory of the $\mathrm{CHICH}$ for performing specific tests. All tests were performed by a qualified pathologist having more than 10 years of experience after post-graduation to diagnose endocrine complications. Endocrine complications were labeled as derangement in any one of the following: diabetes, defined as fasting blood sugar (FBS) > $126 \mathrm{mg} / \mathrm{dl}$ on 2 different occasions; or hypothyroidism as free T4 (FT4) $<0.93 \mathrm{ng} / \mathrm{dl}$.

SPSS version 26.0 was used to analyze study data. Age, FBS, FT4, and number of blood transfusions were represented as mean and standard deviation. Qualitative data like gender, age groups, parental consanguinity, residential status, diabetes and hypothyroidism were shown as frequencies and percentage. Effect modifiers like age, number of blood transfusions per months, disease duration, gender, parental consanguinity and residential area were controlled by making stratified tables. Chi-square test was employed note their effects on outcome considering p-value $<0.05$ as significant.

\section{RESULTS}

Out of 160 cases, 101 (63.1\%) were male and 59 (36.9\%) female. Overall, mean age was $6.79+2.10$ years (ranging 2-11 years). Majority of our study cases, 115 (71.9\%) were aged more than 5 years while 90 (56.2\%) were living in urban areas. Mean disease duration among study cases was $4.18+2.43$ years whereas 114 (71.3\%) had disease duration of more than 1 year. Mean number of transfusions in our study cases was $3.16+1.14$ while $128(80.0 \%)$ had to undergo blood transfusion more than twice per month. Of these 160 study cases, parental consanguinity was positive in 122 (76.2\%). Table-I showing characteristics of study participants.

Mean FBS level was $117.28+32.43 \mathrm{mg} / \mathrm{dl}$ and diabetes was noted in $70(43.8 \%)$ cases. Mean FT4 was $0.99+0.12 \mathrm{ng} / \mathrm{dl}$ and hypothyroidism was noted in $32(20.0 \%)$ cases. Endocrine complications were noted in 102 (36.8\%) cases as shown in Figure-1.

Table-Il is showing endocrine complications were stratified with regards to gender, age, residential status, disease duration, no. of blood transfusions and parental consanguinity. Age above 5 years, 
area of residence as rural, duration of disease above 1 year, number of blood transfusions above 2 and parental consanguinity were found to be significantly associated with the presence of endocrine complications $(p<0.05)$.

\begin{tabular}{|l|c|c|}
\hline \multicolumn{2}{|c|}{ Characteristics } & Number (\%) \\
\hline \multirow{2}{*}{ Gender } & Male & $101(63.1 \%)$ \\
\hline \multirow{2}{*}{$\begin{array}{l}\text { Age Groups } \\
\text { (Years) }\end{array}$} & Female & $59(36.9 \%)$ \\
\hline Residential Status & $<5$ & $45(28.1 \%)$ \\
\cline { 2 - 3 } & Rural & $115(71.9 \%)$ \\
\hline $\begin{array}{l}\text { Disease Duration } \\
\text { (Year) }\end{array}$ & $<1(43.8 \%)$ \\
\hline $\begin{array}{l}\text { Number of } \\
\text { Transfusions Per } \\
\text { Month }\end{array}$ & $>1$ & $90(56.2 \%)$ \\
\hline Parental & $<2$ & $114(71.2 \%)$ \\
\hline Consanguinity & Yes & $128(20.0 \%)$ \\
\hline Diabetes Mellitus & No & $122(76.0 \%)$ \\
\hline Yes & $38(23.8 \%)$ \\
\hline Hypothyroidism & No & $70(43.8 \%)$ \\
\hline
\end{tabular}

Table-I. Characteristics of study participants $(n=160)$

\section{DISCUSSION}

Thalassemias are known to be from a heterogeneous group of inherited abnormalities of haemoglobin synthesis in the shape of life threatening anaemia and require regular blood transfusion to survive. ${ }^{11}$

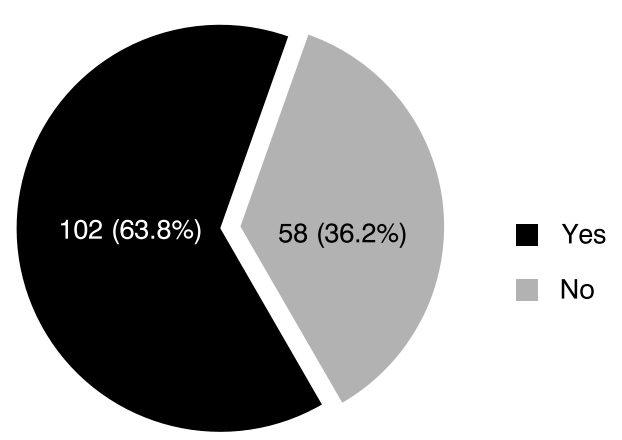

Figure-1. Presence of endocrine complications among study cases $(n=160)$

Thalassemias are more commonly seen in Mediterranean, South East Asia and Middle Eastern countries. ${ }^{12}$ With improvements in the treatment of malnutrition and communicable ailments, $\beta$-thalassemia major cases who used to die in the younger ages are now living long enough to find medical care. But, in a developing country like Pakistan, $\beta$-thalassemia major still poses a major threat with rising burden of the disease while adequate treatment like blood transfusion along with iron chelation and bone marrow transplants are afforded by a very minute population. Prevention remains the way forward as a 20-year control program in Sardinia depicted a decline in the incidence of $\beta$-thalassemia major from $1: 250$ live births to $1: 4000 .^{13}$

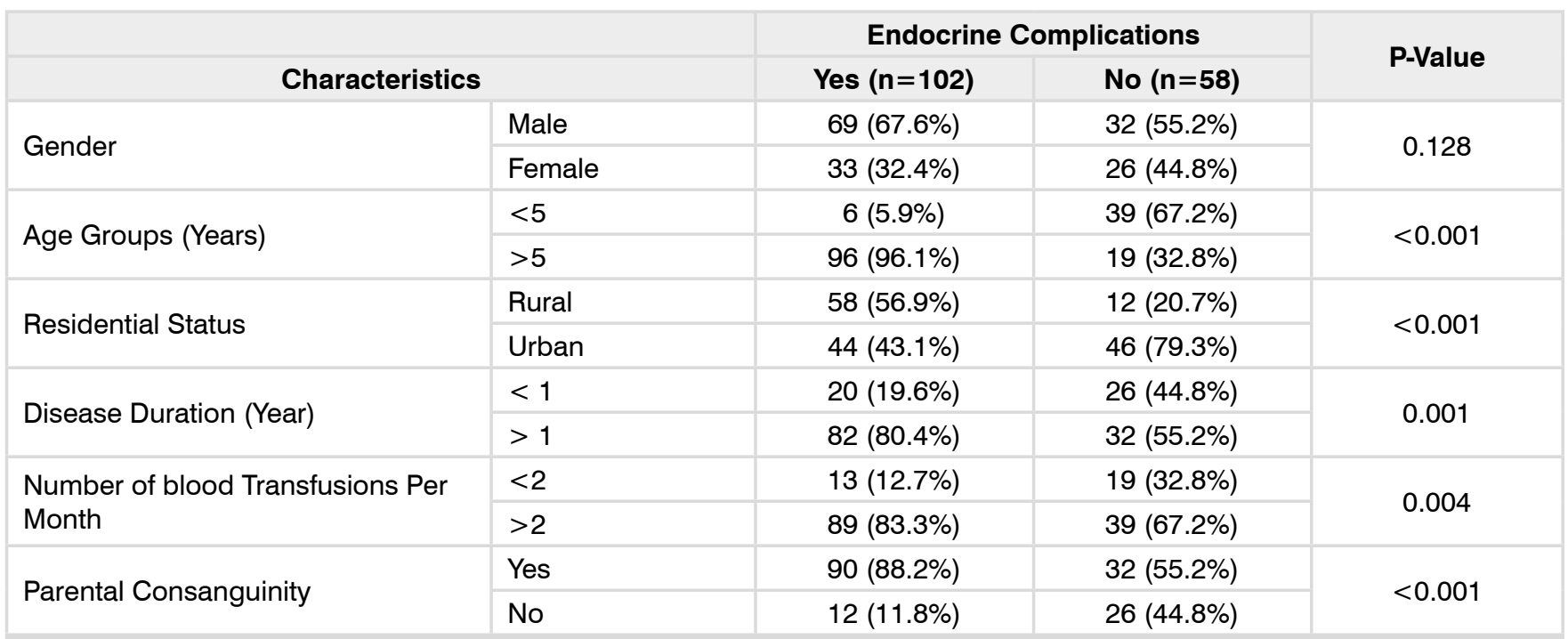

Table-II. Stratifications of endocrine complications with regards to study variables 
A ten-year control program also showed a significant decline (2.53 to 0.82 cases / 1000 live births) in South Iran. ${ }^{14}$ Strategies like population screening along with genetic counseling, prenatal diagnosis and termination of affected pregnancies are some of the most potent components of devising a control program. In our country, the exact burden of Thalassemias are not known as most of the cases are thought to live in rural localities, however, those who live in urban areas have access to prenatal evaluation which is provided by charity organizations most often.

In the present study, we noted that majority of the cases, $63.1 \%$ were male. Qurat-ul-Ain LA et al found $65.7 \%$ of the cases with $\beta$-thalassemia to be males. ${ }^{15}$ Ejaz MS et al from Karachi also reported $54 \%$ of their study participants with $\beta$-thalassemia major to be males which is again in compliance with the results of present study. ${ }^{16}$ Tehseen $Q$ et al also recorded $59 \%$ of the cases with $\beta$-thalassemia to be male. ${ }^{17}$

Overall, mean age among study cases was noted to be $6.79+2.10$ years (ranging 2-11 years) whereas there was no statistical difference between male and female children $(6.93+2.20$ years vs. $6.56+1.92$ years, $p=0.284)$. We also noted that most, $71.9 \%$ children were aged $>5$ years. Qurat-Ul-Ain LA et al found similar findings in terms of age of the study participants. ${ }^{15}$ Safdar $S$ et al in their multi-central study noted mean age among thalassemic children to be $9.40+5.66$ years which is a bit more than what we noted. ${ }^{18}$ Tehseen $Q$ et al found mean age of the cases with thalassemia to be $10.80+3.44$ years which again higher than what we got. ${ }^{17}$ Younger age among our study cases indicate early identification of endocrine complications which can provide us chance to manage and monitor these complications early in the lives of affected case, which in turn, can improve the quality of life of these children.

We found that majority, $56.2 \%$ cases belonged to urban areas of living. Mean disease duration was $4.18+2.43$ years among our cases whereas $71.3 \%$ had disease duration $>1$ year. Ejaz MS et al from Karachi found similar findings. ${ }^{16}$ Tehseen
$Q$ et al found mean duration of illness of their cases to be $8.23+3.15$ years which is more than what we reported. ${ }^{17}$ This could be elaborated in terms of overall lower mean age among our study participants.

Mean number of of transfusions was $3.16+1.14$ in this study while $80.0 \%$ had to undergo blood transfusion more than twice per month. Safdar $S$ et al also noted similar results in another local study. ${ }^{18}$

Of these 160 study cases, parental consanguinity was positive in 122 (76.2\%). Local data has also found in the past that $70.35 \%$ cousin marriages were reported among cases with thalassemia. ${ }^{15}$ A study conducted by Safdar $S$ et al observed $72.8 \%$ parental consanguinity. ${ }^{18}$

Mean Fasting blood sugar level was 117.28+32.43 $\mathrm{mg} / \mathrm{dl}$ and diabetes was noted in $43.8 \%$ cases. Tehseen $Q$ et al reported frequency of diabetes as $25 \%$ which is lower than what we noted. ${ }^{17}$ Mean FT4 was $0.99+0.12 \mathrm{ng} / \mathrm{dl}$ and hypothyroidism was noted in $20.0 \%$ in this study. Endocrine complications were noted in $36.8 \%$ of our study cases. Adil et al from Karachi has reported that $29.4 \%$ thalassemic children had diabetes, $11.8 \%$ had hypothyroidism. ${ }^{9}$ Hypothyroidism is usually asymptomatic in the pre-clinical phase while some commonest features of mildmoderate hypothyroidism are growth retardation, decreased activity, above normal weight and low schooling performance. In these individuals, thyroid gland in not always palpable while thyroid antibodies are frequently reported as negative and ultrasonography of the thyroid depicts irregular echo patterns which thickening of the thyroid capsules. ${ }^{19}$ Satwani et al in another local study noted higher proportion (57.14\%) of children with thalassemia to have endocrine complications. ${ }^{10}$ These findings elaborate that frequency of endocrine complications among children with $\beta$-thalassemia major is high.

Our study had few limitations as well. We were unable to correlate the impact of endocrine complications on the overall quality of life of our children. We also did not have any control group 
in order to compare the extent of risk of these endocrine abnormalities among our population. We also did not note commonest clinical features and symptoms among patients who had endocrine complications which would have given us better insight about the pattern of these abnormalities.

\section{CONCLUSION}

Very high frequency of endocrine complications was noted in the present study among children having thalassemia. Endocrine complications were significantly associated with age, residential status, number of blood transfusions per month, disease duration and parental consanguinity. An awareness campaign must be launched to create awareness among general public regarding prenatal diagnosis and pre-marital screening of thalassemia particularly among affected families to eradicate this menace from our society.

\section{ACKNOWLEDGEMENT}

The researchers would like to thank Muhammad Aamir for his volunteer and worthy assistance in statistical analysis of this study.

Copyright@ 12 Sep, 2020.

\section{REFERENCES}

1. Trompeter S, Cohen A. Blood transfusion. In: Cappellini MD, Cohen A, Porter J, editors. Guidelines for the management of transfusion dependent thalassaemia (TDT). Nicosia (CY): Thalassemia International Federation; 2014.

2. Karim MF, Ismail M, Hasan AM, Shekhar HU. Hematological and biochemical status of betathalassemia major patients in Bangladesh: A comparative analysis. Int $\mathrm{J}$ Hematol Oncol Stem Cell Res. 2016; 10(1):7-12.

3. Kountouris P, Lederer CW, Fanis P, Feleki X, Old J, Kleanthous $M$. IthaGenes: An interactive database for haemoglobin variations and epidemiology. PLOS One. 2014; 9(7):e103020.

4. Olivieri NF, Brittenham GM. Management of the thalassemias. Cold Spring Harb Perspect Med. 2013; 3. pii: a011767.
5. Goss C, Giardina P, Degtyaryova D, Kleinert D, Sheth $S$, Cushing M. Red blood cell transfusions for thalassemia: results of a survey assessing current practice and proposal of evidence-based guidelines. Transfusion. 2014; 54:1773-81.

6. Angelucci E, Matthes-Martin S, Baronciani D, Bemaudin F, Bonanomi S, Capalleni MD, et al. EBMT Inborn Error and EBMT Paediatric Working Parties Hematopoietic stem cell transplantation in thalassemia major and sickle cell disease: Indications and management recommendations from an international expert panel. Haematologica. 2014; 99:811-20.

7. De Sanctis V1, Soliman AT, Elsedfy $H$, Skordis $N$, Kattamis $C$, Angastiniotis $M$, et al. Growth and endocrine disorders in thalassemia: The international network on endocrine complications in thalassemia (I-CET) position statement and guidelines. Indian $\mathrm{J}$ Endocrinol Metab. 2013; 17(1):8-18.

8. Motta I, Bou-Fakhredin R, Taher AT, Cappellini MD. Beta thalassemia: New therapeutic options beyond transfusion and iron chelation. Drugs 2020; 80:105363.

9. Adil A, Sobani ZA, Jabbar A, Adil SN, Awan S. Endocrine complications in patients of beta thalassemia major in a tertiary care hospital in Pakistan. J Pak Med Assoc. 2012; 62(3):307-10.

10. Satwani H, Raza J, Alam M, Kidwai A. Endocrinal complications in Thalassemias: Frequency and association with serum ferritin levels. Pak Paed J. 2005; 29(3):113-9.

11. Ansari SH, Shamsi TS, Ashraf M, Farzana T, Bohray $M$, Perveen $K$, et al. Molecular epidemiology of $\beta$-thalassemia in Pakistan: Far reaching implications. Indian J Hum Genet. 2012; 18(2):193-7.

12. De Sanctis V, Kattamis C, Canatan D, Soliman AT, Elsedfy $\mathrm{H}$, Karimi $\mathrm{M}$, et al. $\boldsymbol{\beta}$-Thalassemia Distribution in the Old World: An ancient disease seen from a historical standpoint. Mediterr J Hematol Infect Dis. 2017; 9(1):e2017018.

13. Cao A, Rosatelli MC, Galanello R. Control of $\beta$-thalassemia by carrier screening, genetic counselling and prenatal diagnosis: The Sardinian experience. Ciba Found Symp. 1996; 197:137-51.

14. Karimi $\mathrm{M}$, Jamalian $\mathrm{N}$, Yarmohammadi $\mathrm{H}$, Askarnejad A, Afrasiabi A, Hashemi A. Premarital screening for $\beta$-thalassemia in Southern Iran: Options for improving the program. J Med Screen. 2007; 14:62-6. 
15. Qurat-ul-Ain LA, Hassan M, Rana SM, Jabeen F. Prevalence of $\beta$-thalassemic patients associated with 97 consanguinity and anti-HCV- antibody positivity-a cross sectional study. Pak J Zool 2011; 43(1):29-36.

16. Ejaz MS, Baloch S, Arif F. Efficacy and adverse effects of oral chelating therapy (deferasirox) in multitransfused Pakistani children with beta-thalassemia major. Pak J Med Sci. 2015; 31(3):621-5.
17. Tehseen $Q$, Bari A, Bano I, Jabeen $U$, Rathore AW. Frequency of impaired glucose tolerance in beta thalassemia major patients. Pak Paed J. 2017; 41(3):131-6.

18. Safdar S, Mirbahar A, Sheikh MA, Taseer IH, Mustafa A, Ali Z, Bashir F, et al. Economic burden of thalassemia on parents of thalassemic children: A multi-centre study. Pak J Med Res. 2017; 56(3):68-72.

19. Borgna-Pignatti $C$. The life of patients with thalassemia major. Haematologica. 2010; 95:345-348.

\section{AUTHORSHIP AND CONTRIBUTION DECLARATION}

\begin{tabular}{|c|l|l|l|}
\hline Sr. \# & \multicolumn{1}{|c|}{ Author(s) Full Name } & \multicolumn{1}{|c|}{ Contribution to the paper } & Author(s) Signature \\
\hline 1 & Syed Zagham Ali & $\begin{array}{l}\text { Data collection, Data } \\
\text { analysis, Drafting. } \\
\text { Methodology, Literature } \\
\text { Review. }\end{array}$ \\
\hline 3 & Sana Waqar & $\begin{array}{l}\text { Wiscussion Data } \\
\text { interpretation. }\end{array}$ \\
\hline 4 & Asim Khurshid & $\begin{array}{l}\text { Study concept, Supervision, } \\
\text { Proof reading. }\end{array}$ \\
\hline
\end{tabular}

